\title{
O CARTAZ MIDIATIZADO: um dispositivo de circulação interacional
}

\author{
Manoella Neves ${ }^{1}$
}

Resumo: O texto é registro de parte de um trabalho de tese em andamento cujo objeto empírico é o cartaz utilizado nas manifestações de junho de 2013 no Brasil e pesquisado a partir dos estudos em midiatização. Destaca-se a presença dos cartazes nas ruas e nas redes sociais digitais, constituindo-se como suporte responsivo, ativo, no processo comunicacional; como dispositivos da circulação interacional, nas redes e nas ruas.

Palavras-chave: Midiatização, cartaz, manifestações, dispositivo, circulação interacional.

Abstract: The text is part record of an ongoing thesis whose empirical object is the poster used in the manifestations of June 2013 in Brazil and researched from the studies in mediatization. It stands out the presence of the posters in the streets and digital social networks, constituting as responsive, active support in the communicational process; as devices of the interactional circulation, in the networks and in the streets.

Keywords: Mediatization, poster, manifestations, dispositive, interactive circulation.

\section{Introdução}

O texto a seguir é o registro de parte de uma pesquisa de tese em desenvolvimento que consiste em observar usos e tentativas de práticas e apropriações de cartazes nas manifestações contemporâneas, com foco nas jornadas de junho de 2013 no Brasil. Da presença dos cartazes nas ruas e nas redes sociais digitais e estudando-os dentro do Programa de Pós Graduação em Ciências da Comunicação da Unisinos na Linha de pesquisa 4, Midiatização e processos sociais, foi feito um registro sobre a compreensão do objeto de estudo como suporte responsivo, ativo, no processo comunicacional; como dispositivos da circulação interacional nas ruas e nas redes. Para tanto, parte-se da observação de alguns cartazes que foram registrados nas coberturas de sites jornalísticos e que também se encontraram nas mídias sociais digitais, principalmente no Facebook.

Para organizar o argumento de pesquisa e deste artigo constituíram-se algumas inferências. Uma delas é a de que os cartazes apresentam uma lógica de midiatização própria. O cartaz parece ser utilizado como 'voz' de quem o porta, tais como os balões das histórias em quadrinhos. Confeccionado unicamente para aquele evento, o cartaz se multiplica quando registrado e postado em uma rede social digital, apresentando-se como um dispositivo de

\footnotetext{
${ }^{1}$ Professora da Universidade Federal de Alagoas (UFAL). Aluna de doutorado do Programa de Pós-Graduação em Comunicação da Universidade do Vale do Rio dos Sinos (Unisinos/São Leopoldo-RS). Bolsista PRODEP/UFAL. E-mail: manoellaneves@ hotmail.com.
} 
circulação interacional. E como ensina Deleuze (FOUCAULT, 1990), desmaranhar as linhas de um dispositivo é traçar um mapa e percorrer terras desconhecidas. O ponto de partida deste traçado é a compreensão de que o cartaz das manifestações contemporâneas é de natureza midiatizada.

\section{Do que se apreendeu sobre midiatização a partir da pesquisa}

Midiatização está relacionada ao modo como a mídia permeia e se confunde com outros campos ou instituições sociais. Este conceito pressupõe a interrelação entre mídia, cultura e sociedade, uma vez que a mídia atravessa a sociedade contemporânea, não podendo ser considerada como algo à parte das instituições culturais e sociais. Desse modo, as instituições também alteram seus modos de apresentar-se. Suas formas de atuação foram modificadas dado que a mídia se torna parte do funcionamento dos outros campos. Alteradas pelas lógicas midiáticas, as instituições se configuram de modo diferente de outros tempos e as manifestações também se apresentam reconfiguradas. No entanto, para quem estuda o campo da comunicação, não se trata de observar a mídia como causa desta modificação, mas, sobretudo, que lógicas de midiatização tensionam nas manifestações contemporâneas.

Estas lógicas apresentam uma processualidade não aleatória nem dispersa, apresentando certo grau de racionalidade - daí a pertinência das palavras lógica ou lógicas. Mesmo não atendendo a requisitos de lógica formal, de um estudo normativo, há uma aquiescência tácita na logicidade do processo (BRAGA, 2015). As lógicas de midiatização apresentam em seu processo certos padrões e permanências assim como rupturas e dispersões. Quanto ao objeto cartaz, como suporte em manifestações contemporâneas, inseridos em processos midiáticos, apresentam processos interacionais tácitos com certo nível de espontaneidade - cujo modo de apropriação, em contextos midiáticos de manifestação, ocorre à revelia de quem o sustenta.

A cultura comunicacional se demarca pelo fenômeno da midiatização. Todos os setores sociais desenvolvem tentativas para se dotar dos recursos da mídia em suas interações. Para quem estuda os fenômenos da midiatização, Braga (2015) ensina que é preciso observar como as lógicas dos processos midiáticos se manifestam em casos concretos, observando seu surgimento, suas variações, suas manifestações e suas transformações, além de descobrir e acionar efetivamente os materiais que determinam os gestos e a coerência entre os usuários, e 
entre estes e os objetos do processo. Compreender casos particulares e fazer previsões é o que se espera de um conhecimento científico. Os estudos em midiatização têm permitido refletir sobre os processos interacionais, sua dinâmica relacional e como se configuraram tais processos nas manifestações de junho de 2013 - onde podem ser encontrados dispositivos de captura e, portanto, de captura daqueles processos, tais como os cartazes em contexto de manifestação contemporânea.

O conceito de midiatização revelou-se produtivo para a compreensão de como a mídia se difunde para, se confunde com e influencia outros campos ou instituições sociais, tais como a política. O direcionamento de Hjavard (2012) é entender as maneiras pelas quais as instituições sociais e os processos culturais mudam de caráter, função e estrutura em resposta à onipresença da mídia. $\mathrm{O}$ autor diz ainda que a primeira vez que o termo foi usado, referia-se ao impacto dos meios e comunicação na comunicação política e a outros efeitos neste campo. A política midiatizada é a que perdeu sua autonomia, que se tornou dependente, em suas funções centrais, dos meios de comunicação de massa e é continuamente moldada pelas interações com eles (idem; ibdem, p.57).

Para Hjavard (2012), portanto, midiatização da sociedade está relacionada ao processo pelo qual a sociedade, progressivamente, está submetida ou tornou-se dependente da mídia e de sua lógica. Ao explicar o termo 'lógica da mídia' o autor refere-se ao modus operandi institucional, estético e tecnológico dos meios, incluindo as maneiras pelas quais eles distribuem recursos materiais e simbólicos e funcionam com a ajuda de regras formais e informais. Hjavard (op.cit.) explica que ao estudar midiatização busca-se entender as maneiras pelas quais as instituições sociais e os processos culturais mudaram de caráter, função e estrutura em resposta à presença da mídia. Entendendo que parte da influência exercida pela mídia decorre do fato de que ela se tornou parte do funcionamento de outras instituições, tendo também alcançado um grau de autodeterminação e autoridade que obriga essas instituições, de algum modo, a submeter-se a sua lógica. Diante desta inserção mais profunda da mídia no tecido social, mudam algumas práticas, entre elas os modos de se realizar as manifestações de rua.

Ao contrário do encaminhamento de Hjarvard (2012), Braga (2015) entende que não se trata de pensar apenas em uma "incidência da mídia" (mídia como "causa"); mas, sobretudo nas mídias como processo desenvolvido por quem as aciona. Ou seja: que usos específicos das mídias foram feitos, desde os cartazes, até a televisão, o rádio e os processos 
de rede social? Braga (ibdem) demarca bem a diferença entre lógica da mídia e lógica da midiatização. Esta com contornos mais amplos que os das instituições midiáticas, acrescentando alternativas entre o midiático e o presencial, com suas incidências mútuas.

Seguindo a ideia deste autor, a cultura comunicacional se demarca pelo fenômeno da midiatização e todos os setores sociais desenvolvem tentativas para se dotar dos recursos da mídia em suas interações. Dois âmbitos básicos oferecem lógicas midiáticas bem estabelecidas: 1) conjunto de processos empresariais e profissionais que conduzem as atividades de indústria cultural; 2) Processos que derivam da materialidade das tecnologias midiáticas e de suas combinações. Os processos midiáticos, como processos sociais, apresentam determinados padrões, com certa coerência e racionalidade interna que articula diversos movimentos e que também relacionam tais ações com os propósitos do processo. Estas lógicas ora são claras ora subliminares e

[...] não parecem esgotar toda a processualidade interacional da midiatização. Junto com os novos meios e dispositivos técnicos, aparecem outros procedimentos, muitos dos quais experimentais, acionados pelos diversos setores sociais, que desenvolvem e testam outras lógicas. Mesmo que em parte derivadas de lógicas mais estabelecidas, é preciso apreender especificidades e experimentações na direção de outras regras, imediatas ou potenciais (BRAGA, 2015, p. 16).

De acordo com Braga (2006), a palavra "mediatização" pode ser relacionada a, pelo menos, dois âmbitos sociais. Um, trata processos sociais específicos que passam a se desenvolver (inteira e parcialmente) segundo lógica da mídia - entendendo então mediatização de instâncias como a da política, do entretenimento e da aprendizagem. Outro, em um nível macro, refere-se à mediatização da própria sociedade. Abordando a questão macro, o autor propõe uma visão sobre mediatização como processo interacional em marcha acelerada para se tornar o processo de referência, acenando mais ajustadamente a reformulações sociotecnológicas de passagem dos processos mediáticos à condição de processualidade interacional de referência.

A expressão 'referência', em parte, decorre da consideração de determinados processos como principais ou prevalecentes. Os demais processos interacionais teriam estes como parâmetro, como critérios de validade e definidores de lógicas centrais. Um processo interacional de referência, em um determinado âmbito, 'dá tom' aos processos subsumidos. Mas o fato de que um processo interacional assim se apresente, não corresponde a 'anular' outros processos, mas a funcionar como 'organizador principal da sociedade'. Então, Braga 
(ibdem) entende que os processos interacionais de referência são os principais direcionadores na construção da realidade social onde a sociedade constrói esta realidade por meio de processos interacionais pelos quais os indivíduos, grupos e setores da sociedade se relacionam.

Em um processo inexorável de mudanças, sobretudo a partir do século $\mathrm{XX}$, a sociedade encontra-se entre a transição da escrita para a crescente mediatização de base tecnológica. Os modos segundo os quais a sociedade realiza, escolhe e direciona as possibilidades sociais, a partir dos processos de interação, constroem a realidade. Articulações complexas entre participantes da sociedade e o acervo diverso de dados constituem as interações sociais contemporâneas. A sociedade contemporânea estaria em processo, em vias de mediatizar-se por completo, mas sendo evidenciadas algumas lacunas que caracterizariam o que Braga (2007) chama de 'incompletude' deste processo, referindo-se a insuficiências interacionais dos processos mediatizados para elaborar modos consistentes e defensáveis da construção social da realidade vivida.

Para Ferreira, midiatização é uma perspectiva epistemológica que deve pensar em termos de circulação e ensina que

\footnotetext{
Estudar a circulação é produzir inferências possíveis (questões e proposições) sobre os valores (des)construídos socialmente a partir de usos e práticas relacionáveis às interações com os dispositivos midiáticos, adotando como referência preliminar o campo observável constituído por materialidades difusas e distribuídas. Na perspectiva da inferência, os valores em jogo não são visíveis nem relacionáveis completamente. Sempre inferenciais, são provisórios e possíveis para o investigador, assim como o são os participantes do jogo comunicacional (2013, p.142).
}

Este autor diz ainda sobre circulação que ele infere, pelo campo observacional, que a circulação é uma problemática que se destaca entre os processos intermidiáticos (entre dispositivos) e intramidiático (no âmago do dispositivo). Ferreira (op. cit.) sugere que o objeto primeiro da circulação seja a interação entre dispositivos midiáticos, com suas diversidades e semelhanças. Na dinâmica observada no contexto em pesquisa, a interação capital entre os dispositivos cartazes fica entre a rua e a rede. Numa dinâmica mais pontual, neste 'estar entre', a lógica da midiatização se apresenta sobre os processos mais específicos quanto ao uso do cartaz nas jornadas de junho de 2013 e nas manifestações que se sucederam.

Braga (2010) indica um caminho necessário para se pensar o âmbito de questionamento comunicacional, ensinando que há de se buscar um desentranhamento da 
comunicação - pois esta não existe em estado puro - e é disciplina em constituição. Remete a um exercício de ater-se ao campo de origem buscando localizar quais são as perguntas epistemológicas da comunicação na aproximação com outro campo. E o autor dá o aporte para o desentranhar: aproximar instituições sociais e linguagens, a partir dos dispositivos interacionais em que se organizam os processos midiáticos. E Deleuze complementa a ideia e orienta ao afirmar que

En todo dispositivo debemos desenmarañar y distinguir las líneas del pasado reciente y las líneas del futuro próximo, la parte del archivo y la parte de lo actual, la parte de la historia y la parte del acontecer, la parte de la analítica y la parte del diagnóstico (in FOUCAULT, 1990, p.160).

Quanto ao desentranhamento, corresponde este, a apresentar hipóteses e ao fazer perguntas para além das que já foram feitas pelas demais 'ciências de vizinhas', gerando questões que estas não fariam, mas que podem ser acionadas pela interface que mantém. E o suporte cartaz é um objeto de estudo privilegiado para a comunicação com interface na história e na política, por exemplo.

\section{Lógicas de midiatização e circulação}

Para o diálogo acontecer, necessário se faz um espaço. A partir das lógicas de midiatização, tal espaço remete ao da circulação. Os cartazes, que passam nas ruas e nas redes sociais na internet, permitem observar uma nova forma de ambientar a comunicação midiática, de acordo com operações deste dispositivo de circulação.

Disso não se pode resultar da supressão dos lugares de produção e da recepção de discursos, mas sua subordinação a uma nova configuração de regimes de discursividades nos quais o trabalho enunciativo está preso. Trata-se da ordem interdiscursiva onde circulação se aloja - como 'terceiro' - e se oferece como um novo lugar de produção, funcionamento e regulação de sentidos (FAUSTO NETO, 2010, p. 4).

Da ambiência de interface dos cartazes - e considerando que eles nas manifestações 'respondem' à política e à mídia -, pode-se inferir a amplitude da problemática que traz em seus usos e apropriações com lógica própria. Ao circular podem ser moldados à revelia de quem o utiliza. 
De um lado, gramáticas fortemente estruturadas, no seio das instituições, de discursos midiáticos. E de outro, a emergência de multiplicidades de gramáticas que se fundam e se orientam em diversidades de lógicas oriundas do mundo dos atores e dos indivíduos, articulando-os a um trabalho. No lugar da homogeneização de sentidos, a diversidade e heterogeneidade de estratégias (FAUSTO NETO, 2010, p. 10).

E quanto às estratégias e ao caráter mais comunicacional, os cartazes parecem remeter a um slogan publicitário como uma ideia-resumo e o conjunto deles marca permite

Observar como as lógicas se manifestam em casos concretos, observar seu surgimento, suas variações, sua manutenção e transformação [...] Descobrir e acionar efetivamente os materiais que determinaram os gestos e a coerência entre os usuários e entre estes e os objetivos do processo (BRAGA, 2015, p.20).

Por este caminho, é possível descobrir a ativação de processos interacionais; quais “códigos" (padrões, regras, lógicas) de interação são acionados, como são usados, que relações são organizadas entre aquelas posições, que processos são inventados ad-hoc para a situação. Deste modo, deseja-se deixar claro que, embora se observe as posições políticas indicadas nos cartazes, investigam-se as circunstâncias especificas do próprio uso.

Observar como as lógicas se manifestam em casos concretos, seu surgimento, suas variações, sua manutenção e suas transformações é a tentativa de dizer sobre os processos, uma vez que as lógicas os caracterizam. Do estudo sobre os usos e apropriações de cartaz, busca-se a identificação de lógicas embutidas no modo de fazer uma manifestação popular na contemporaneidade, busca-se, portanto dizer sobre este novo processo. Não somente sobre os modos de se fazer manifestação, mas de interação comunicacional - inserida em uma sociedade em vias de midiatização apresenta-se dinâmica, diferida e difusa.

Braga (2011) afirma que o objeto da comunicação deve ser apreendido como um tipo de processo epistemologicamente caracterizados por uma perspectiva comunicacional, cujas proposições possam ser testadas pela capacidade de explicar os processos que sejam claramente 'fenômenos comunicacionais', relacionando temas e questões que sejam da preferência do pesquisador do campo. E assim, propõe considerar um objeto de estudo mais amplo que os meios de comunicação, a saber, as interações e estratégias comunicacionais tácitas nos cartazes.

Observando os cartazes, suas reivindicações e proposições, como indicadores (índices), é possível fazer inferências a respeito dos processos interacionais acionados - e, portanto, da especificidade das jornadas de 2013, em contraste com processos e códigos das 
passeatas mais habituais (partidárias e/ou sindicais). Desse modo, evidencia-se a dispersão de falas e processos nos modos de se apresentarem as manifestações de junho de 2013 no Brasil.

Entre a produção e recepção de mensagens, verifica-se a intervenção da técnica e deste modo uma alteração na circulação das mensagens. Com isso, o processo interacional passa a mover-se mais através de descontinuidades e contrastes nas relações entre produtor e receptor, cujos discursos suscitam a possibilidade de efeitos mais variados, múltiplos, dispersos e não convergentes, com desarticulação entre lógicas de oferta e de mensagem e o destino que lhe é dado por seus usuários. E desta dispersão a linguagem é instância que organiza o trabalho de enunciação dos sujeitos em produção e recepção.

No caso da referida pesquisa de doutorado, a observação feita identifica nos usos e apropriações do cartaz de manifestação e em toda a ambiência onde ele circula, uma dispersão, sobretudo por estarem em manifestações sem uma organização partidarizada. Desta ausência se identificam lógicas de midiatização diversas e difusas, e a partir de tais lógicas chega-se a reconhecer, no cartaz, certas aproximações (inferenciais) entre instituições sociais (partidos, empresas de comunicação, religiões, para citar algumas) e linguagem.

Os cartazes em questão são 'marcadores' de circulação. Enquanto mensagem, indicam que foi dito algo e que pode ser (re)dito/reeditado, respondido. Enquanto objeto, pode ser (re)utilizado de outro modo. Hashtag é outra configuração do conteúdo do cartaz - e que também marca a circulação - neste caso, nas redes, tematizando sobre o que está circulando.

$\mathrm{Na}$ sociedade em vias de midiatização, evidencia-se novo cenário sócio-técnicodiscursivo. Novas formas de organização da circulação dos discursos e cuja problemática dos efeitos de sentido ganham nova complexidade. Produtores tornam-se receptores e estes se configuram também em produtores de conteúdo frente a um complexo trabalho de linguagem e técnica com operações de dispositivos que geram pistas para procedimentos analíticos que possibilitam a inteligibilidade do funcionamento de tais dispositivos.

Como dito acima, a compreensão da circulação midiática é da ordem interdiscusiva. A circulação se apresenta como um lugar de produção, funcionamento e certa regulação de sentidos, os discursos de emissão e recepção, as gramáticas de produção e de reconhecimento perdem suas marcas de fronteiras. É no espaço da circulação que se realiza o trabalho de negociação e apropriação de sentidos, é nela em que os discursos são propostos e apropriados, é por ela que emergem estratégias cujas lógicas assinalam para a difusão e dispersão, uma vez 
que há uma complexa processualidade nos modos de interação, com dificuldade de domínio sobre suas dinâmicas.

O cartaz foi utilizado nas ruas para expressar uma ideia, sendo 'voz' de quem o portava. Ao 'sair às ruas' foi registrado e postado em rede social digital podendo ser utilizado por quem está inscrito na rede digital na qual circulava - a revelia de quem originalmente o criou. Foi fonte de matérias jornalísticas sendo algumas destas, preenchidas exclusivamente por imagens de cartazes, quase que sem texto. $\mathrm{O}$ cartaz foi replicado na rede, em formato imagem ou de seu conteúdo - 'hashtagzando-se'-, ou surgindo em outra rua, com a mesma ideia em outra cartolina.

Moles (2004) trata o cartaz a partir da perspectiva publicitária nos espaços urbanos, afirmando que este suporte age como bomba de circulação no circuito econômico. A compreensão de circulação adotada nesta pesquisa se vincula à questão comunicacional, referindo-se à circulação de mensagens e sentidos. A circulação no sentido econômico está entre a disponibilização da produção e o acesso ao consumo. Embora tendo o cartaz aqui de forma diferente, a concepção de Moles (op.cit.) interessa, uma vez que o cartaz é um dispositivo no qual se 'disparam' ideias sobre o contexto onde se encontram - no caso - nas manifestações de 2013 no Brasil. Ao dispararem as ideias estas se tornam objeto de interação baseada no estímulo dado pelo conteúdo do cartaz. Ele é um dispositivo que favorece a interação ao mesmo tempo em que a registra e produz nela uma velocidade - dada a natureza sintética do suporte.

O suporte cartaz apresenta-se como dispositivo e através dele o manifestante se inscreve no movimento das ruas - sendo passagem - e diz algo - sendo um meio. O dispositivo é um lugar de inscrição que se transforma em operador de novas condições de produção e recepção e ao mesmo tempo passagem e meio (FERREIRA, 2014, p.147). O conjunto de cartaz formaria então uma comunicação entre diferenças simultâneas, o dialógico, a polifonia - a partir de Bakhtin - e que permite chegar à circulação, uma vez que esta se dá exatamente neste espaço entre produção e reconhecimento. Se a circulação é o lugar da possibilidade de desarticulação entre lógicas de produção e de reconhecimento, a polifonia ai se constitui e o cartaz sinaliza-a.

Aprendeu-se que episódios comunicacionais devem ser entendidos em contexto, e este corresponde às instituições sociais e às linguagens acionadas pela interação. Nos cartazes das jornadas de junho de 2013 - com seu desencadeamento complexo e de motivações dispersas 
(talvez, sendo mais bem reveladas e compreendidas após as de março de 2015) - foram feitas escolhas sobre o que e como dizer, havendo um processo social de seleção, evidenciando-se ai um fenômeno comunicacional. Na propagação e dispersão dos modos de diz, evidencia-se, a partir do uso do cartaz, uma lógica própria de manifestação midiatizada, cuja sociedade saiu às ruas e se viu nas redes sociais digitais, dando-se em espetáculo com roteiros particulares.

Neste contexto de manifestações marcadas pela presença das lógicas de midiatização, observa-se o cartaz como dispositivo de circulação. Sendo os dispositivos midiáticos, de acordo com Ferreira (2013), um lugar de inscrição, entende-se que o cartaz é um registro desta inscrição, e uma vez inscrito, não fica parado, movimenta-se provocando os contextos interacionais por onde passa.

A partir dos dispositivos, entende-se então que há na circulação, a possibilidade de vários efeitos, não conhecidos, a priori. E sua força e complexidade estão na desarticulação entre lógicas de oferta de mensagem e o destino dado pelos usuários. Embora a linguagem seja uma instância que organiza o trabalho enunciativo dos sujeitos em produção e em recepção, o trabalho de produção de sentido se faz em decorrência de um feixe de relações. Sendo a circulação o lugar de embate suprimindo-se a instância mediadora e optando por 'plataformas circulatórias' e arquitetura comunicacional 'todos para todos' (FAUSTO NETO, 2013).

Os cartazes, em especial os utilizados nas manifestações de 2013, são a materialidade do 'sistema circulatório'. A sociedade sai das mídias sociais digitais para as ruas, mesmo com coberta dada pela mídia tradicional, sai da fronteira midiática e viabiliza novas mediações, identificando-se novas estratégias e práticas de relações com a política. Os acontecimentos vividos nas ruas pelos jovens que participaram das manifestações e o que foi dito e divulgado nas redes sociais digitais e na mídia tradicional conduzem para o polo da circulação em que a manifestação enunciada nas ruas e na web constituem um acontecimento de cada um destes lugares: na rua, na rede, na mídia tradicional.

E os cartazes levaram os valores, as reivindicações, as pautas a circularem, em manifestações sem porta-vozes clássicos, sem organizações que as sistematizassem tais como, os movimentos sociais e os partidos políticos, em que eles definiriam palavras de ordem, objetivos de uma ação, procedimentos (tais como acionar os recursos financeiros para fazer faixas e cartazes impressos) para obter maior número de adesão e eficiência na circulação de sua mensagem. Cada um que empunhou um cartaz, levantou sua proposta, seu protesto, sua 
ideia ao seu modo, não havendo uma assinatura institucional que os identifique. Desse modo, as intenções e os efeitos que se presumem não podem mais serem totalmente controlados, não havendo uma linearidade, se estabelecendo a circulação e se mantendo a interação. A linearidade dá lugar à heterogeneidade. Dissolve-se no ato da enunciação a existência de uma noção de equilíbrio, especialmente vínculos possíveis de simetricidade, na medida em que as intenções que os engendram não são controláveis (FAUSTO NETO, 2010, p.9).

E esta dissolução está, sobretudo, nas redes sociais, mas o que dá certa ordem são as hashtgas. O que está no cartaz na rua, torna-se hashtag nas redes sociais. Uma forma de titular uma postagem com possibilidade variada de sentidos, alterado e ressignificado na interação, no movimento dado ao tema dentro e fora da rede. Formado por várias palavras e que juntas tem uma função. Uma unidade significativa organizada em torno de um elemento fundamental, o núcleo parecido ao um sintagma.

Dos cartazes que rodeiam a pesquisa, algumas frases presentes neles também se apresentam em linguagem de comunicação digital. Seguida de hashtag: \#vemprarua e \#ogiganteacordou, compõem e sinalizam uma ideia, mais bem compreendida a partir da observação de usos específicos das expressões, aqui denominas de hashtagização sintagmática. O uso da hashtag também precisa ser entendido em contexto. Tanto no cartaz como sua transposição para hashtag há possibilidade e tendência de desdobramento de diferentes caminhos possíveis, pois marcam o prosseguimento do fluxo comunicacional. As mudanças decorrentes de processos de interação em midiatização modificam crescentemente o perfil, os sentidos e os modos de ação na sociedade. Tchakhotine (1997), ao mencionar à propaganda política dos tempos antigos, aponta para o uso de cartaz (a que ele chama de titulus) que aparecia em desfile, feito de modo primitivo dada impossibilidade técnica para reproduzir um texto em grande número de exemplares. Na contemporaneidade, diante da condição de fazer múltiplas cópias, somadas à tecnologia das mídias sociais digitais evidencia-se a complexificação do processo interacional a que o uso do cartaz remete, com formas e modos de interagir e com desarticulação entre as lógicas da produção e da recepção em um jogo complexo de oferta e reconhecimento. 


\section{O cartaz midiatizado como dispositivo interacional}

O cartaz nasce sintético, sendo parte de um discurso que já surge fragmentado, uma vez que é individualizado. Cada um segura o seu cartaz e diz nele o que deseja sem a necessidade de regulação prévia de um discurso institucionalizado. Como já foi dito, o novo movimento social traz a marca da autonomia da comunicação, permitindo que tal movimento se forme sem o controle do poder da comunicação.

Diante disto, o caráter distinto de cada resposta é a forma específica da respondibilidade de um manifestante. Neles há uma conversação entre vários, respondendo a questões postas por outro circuito midiático. Um exemplo é o que foi dito em uma matéria jornalística na TV é respondido, contestado em cartaz, nas ruas. A resposta é a parte mais visível da circulação em fluxo.

Braga (2006) ensina que no terceiro sistema de processos midiáticos as atividades de respostas produtivas e direcionadoras da sociedade em interação com os produtos midiáticos formam o sistema de resposta social. O sistema de interação social sobre a mídia é um sistema de circulação diferida e difusa. Os sentidos midiaticamente produzidos chegam à sociedade e passam a circular entre pessoas, grupos e instituições impregnando e parcialmente direcionando a cultura. Tal sistema é esse movimento social dos sentidos e dos estímulos produzidos inicialmente pela mídia.

Os conteúdos dos cartazes aparecerem comumente calibrados a partir da existência de outros meios. Os conteúdos estavam sempre mudando a partir da existência de outros meios, expressando valores articulados em atos. No cartaz entre a rua, a mídia tradicional e a rede moldou-se a construção de uma atividade arquitetônica da autoria que se constituiu em pequenos textos (diferidos e difusos) nas sucessivas manifestações em junho de 2013 e que se evidencia como a própria constituição destas manifestações.

O diálogo forma a arquitetônica, ele é uma unidade, mas não de uma difusividade de uma única ideia ou tema, mas uma coesão expressiva inerente às relações dialógicas, interacionais entre várias ideais e vozes. Daí pode-se afirmar que a arquitetônica constituída é a arquitetônica do valor, dos valores em jogo, apreendidos ao jogar o jogo, ao ingressar nas manifestações.

Ferreira (2013) afirma que estudar circulação é produzir inferências possíveis sobre valores (des)construídos socialmente a partir de usos e práticas relacionáveis às interações 
com dispositivos midiáticos. A partir desta concepção, compreende-se que o dialogismos é constitutivo de uma circulação e nela há um conjunto de valores entre os participantes do jogo comunicacional. No caso em estudo, pelas palavras contidas nos cartazes evidencia-se certo confronto de valores e entendimentos e cada cartaz traz sua verve e nela a entonação expressiva que é o tom dado pelo valor. "A entonação expressiva, a modalidade apreciativa sem a qual não haveria enunciação, o conteúdo ideológico, o relacionamento com uma situação social determinada, afetam a significação" (BAKHTIN, 1992, p.15).

Embora uma remeta a outra, as frases: 'O gigante não está mais adormecido' (campanha da Johnnie Walker) e 'O gigante acordou' ou 'verás que um filho teu não foge à luta' (dos cartazes de junho de 2013) apresentam entonações expressivas diferentes frente ao propósito de cada uma delas. Quando se observa a proposta e o contexto de criação da campanha o sentido é oposto ao da frase relacionada, frente ao contexto das manifestações.

Imagem 1: Cartaz: Brasil alterou seu status de "deitado eternamente em berço esplêndido" para "verás que um filho teu não foge à luta".

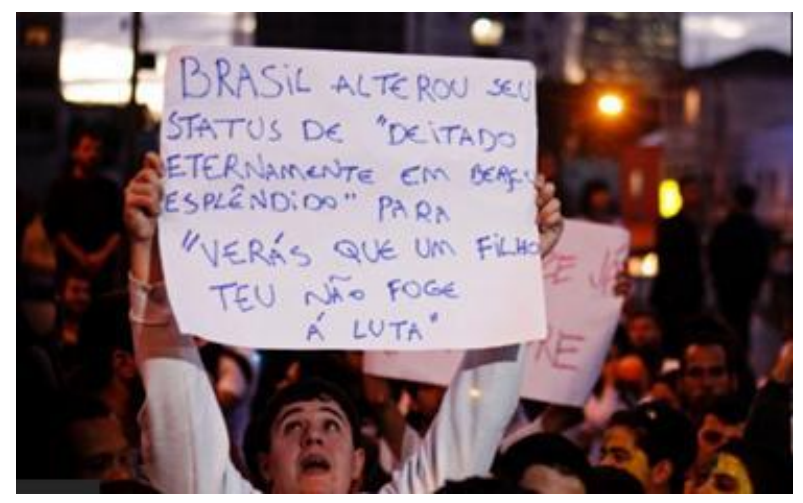

Fonte: Léo Pinheiro/Futura Presse/OUL

Imagem 2: Cenas da Campanha da Johnnie Walker: KeepWalking, Brazil (2011)
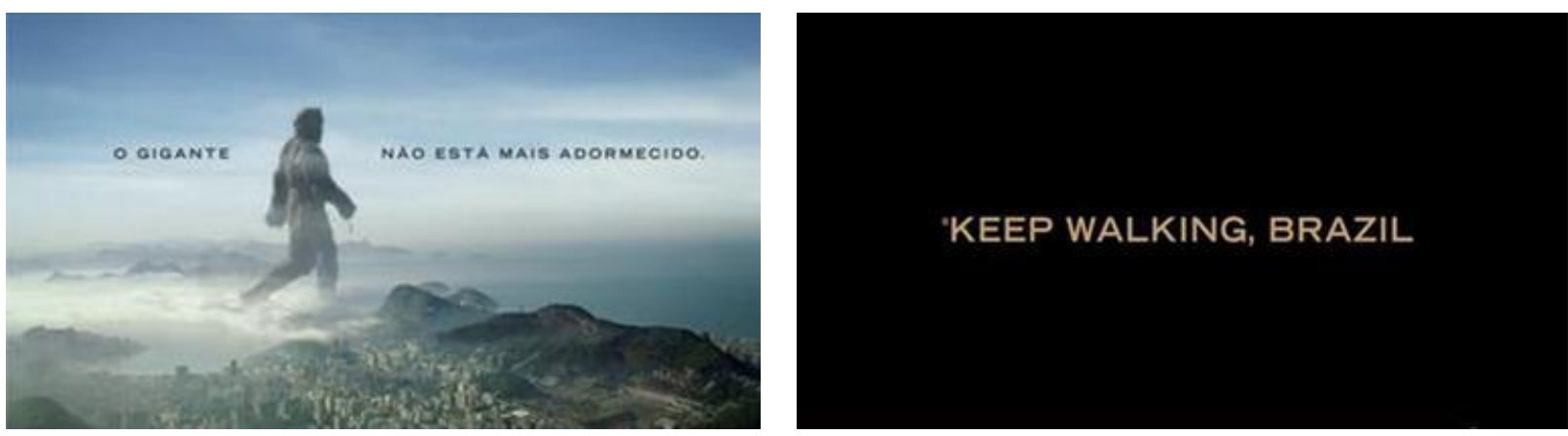

Fonte: NEOGAMA | BBH. KeepWalking, Brazil 
O mesmo ocorre com a campanha da Fiat. 'O vem pra rua' da campanha é um convite à torcida pelo Brasil no esporte, no futebol, no contexto das manifestações a frase torna-se um apelo para ocupar as ruas das cidades brasileiras e 'lutar pelo Brasil'.

\section{Imagem 3: Larga o Candy Crush e vem pra rua}

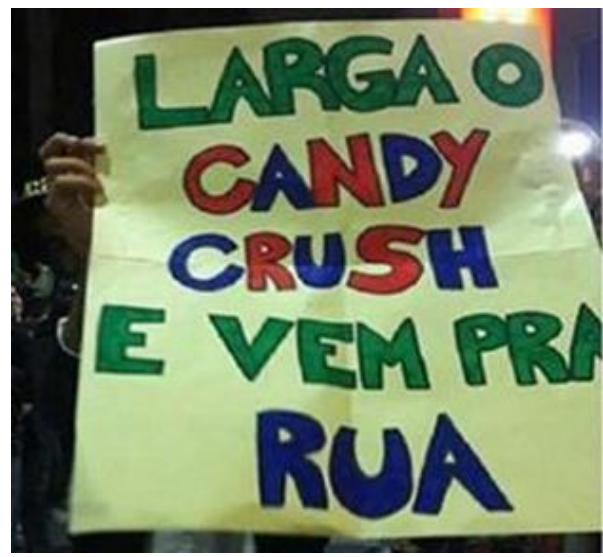

Fonte: Casseta \& Planeta
Imagem 4: Print de cena do comercial da Fiat (2013) - Vem pra rua

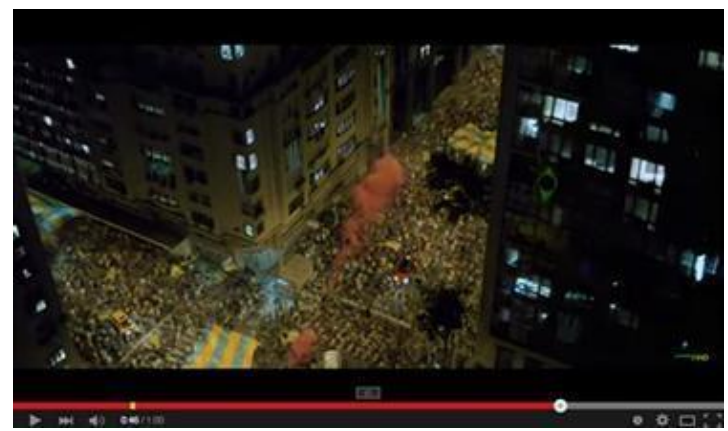

Fonte: Fiat/Youtube

Os produtos circulantes da 'mídia de massa' são retomados em outros ambientes, que ultrapassam a situação de recepção (o espectador diante da tela) e no contrafluxo, passa-se a produzir a partir das respostas que se pretende, espera ou receia, ensina Braga (2012) sobre este 'fluxo adiante'. Entende-se também que toda enunciação compreende uma orientação apreciativa e é à apreciação que se deve o papel criativo nas mudanças de significação, que também são de valores. Tal mudança é sempre uma reavaliação, o deslocamento de uma determinada palavra de um contexto apreciativo para outro. Deste modo chega-se a Castells que diz que

O processo de construção de significado caracteriza-se por um grande volume de diversidade. Existe, contudo, uma caraterística comum a todos os processos de construção simbólica: eles dependem amplamente das mensagens e estruturas criadas, formatadas e difundidas nas redes de comunicação multimídia. Embora cada mente humana individual construa seu próprio significado interpretando em seus próprios termos as informações comunicadas, esse processamento mental é condicionado pelo ambiente da comunicação. Assim, a mudança do ambiente comunicacional afeta diretamente as normas de construção de significado e, portanto, a produção de relações de poder (2013, p.15). 
Cartaz feito no improviso, com uma 'rubrica' própria de seu portador, feito em unidade e exclusivamente para o evento, parece evidenciar uma necessidade e um desejo de expressão para um interlocutor. Como balões de histórias em quadrinhos para o diálogo dos personagens, apresentando sua lógica e humor - ou como diria Bakhtin (1992), uma entonação expressiva. A entonação é o som que o valor faz (CLARK; HOLQUIST, 1998, p. 37). Embora, de natureza diferente das histórias em quadrinhos, o cartaz de manifestação também vem para dizer alguma coisa. De acordo com Tchakhotine (1997) o cartaz de manifestações (assim como carros de som, folhas de papel lançados no alto dos prédios, buzinas, as pichações em muros) é usado também como elemento de uma propaganda com expressão de frase síntese - como os slogans - e do tipo emocional que visa a excitar ao máximo as multidões e é inserido em cortejos que tomam certo caráter carnavalesco. E segundo o mesmo autor, as manifestações são a mais alta expressão do dinamismo político das massas.

As manifestações a partir de 2013 apresentam uma característica de organização através das redes sociais digitais, com permanência das repercussões nestas redes e trazendo forte comparecimento dos indivíduos mais que das instituições (embora elas estejam também). Com a maior presença dos indivíduos, na interação, o discurso se personaliza e se fragmenta. O cartaz indica quem diz sua mensagem - supostamente, quem o sustenta na passeata ou quem o posta como o registro de um momento, na rua em manifestação -, no entanto, não aparece a autoria original de sua mensagem. Os cartazes revelam o que observa Cohn (2014) ao dizer que "há uma estética particular nas manifestações: não desfraldam bandeiras de organizações nem usam faixas pré-confecionadas, não usam palavras de ordem e as chamadas são em cima da demanda foco".

Por sua natureza, o cartaz nasce sintético e seu conteúdo é parte de um discurso que já surge fragmentado, uma vez que é individualizado. Cada um segura o seu cartaz e diz nele o que deseja, mas sempre a partir de um dado contexto e de sua compreensão sobre este momento, sem a regulação prévia de um discurso institucionalizado. O cartaz midiatizado é responsivo, gerador de outros sentidos em um fluxo adiante, portanto, objeto privilegiado para os estudos sobre dispositivo de circulação interacional. 


\section{Referências}

BAKHTIN, M. Marxismo e filosofia da linguagem. São Paulo: Hucitec, 1992.

BRAGA, J. L. Lógicas da mídia, lógicas da midiatização? In: FAUSTO NETO, A., et.al.. Relatos de investigaciones sobre mediatizaciones. 1a ed., Rosario: UNR Editora. Editorial de la Universidad Nacional de Rosario, 2015. E-Book.

O que a comunicação transforma? In: BRAGA, J. L.; FERREIRA, Jairo; FAUSTO NETO, A.; GOMES, P. G. (Orgs.). 10 perguntas para a produção do conhecimento em comunicação. São Leopoldo-RS: Ed. UNISINOS, 2013, p.156-171.

Circuitos versus campos sociais. In: MATTOS, M. Â.; JANOTTI JR, .J; JACKS, N. (Orgs.). Mediação \& Midiatização. Livro Compós 2012. Salvador: EDUFBA, 2012.

Constituição do Campo da Comunicação. Revista Verso e Reverso, São Leopoldo: UNISINOS, XXV (58): p. 62-77, janeiro-abril de 2011. Disponível em: http://revistas.unisinos.br/index.php/versoereverso/article/view/924.

Comunicação é aquilo que transforma linguagens. Revista Alceu, vol. 10 n.20, jan./jun. 2010, p. 41-54. Rio de Janeiro: PUC-RJ, 2010. Disponível em: <http://revistaalceu.com.puc-rio.br/media/Alceu20_Braga.pdf>

Midiatização como processo interacional de referência. In: MÉDOLA, A. S.; ARAÚJO, D. C.; BRUNO, F. (Orgs.). Imagem, visibilidade e cultura midiática: livro da XV Compós. Porto Alegre: Sulinas, 2007.

A sociedade enfrenta sua mídia: dispositivos sociais de crítica midiática. São Paulo: Paulus, 2006.

CASTELLS, M. Redes de Indignação e Esperança. São Paulo: Zahar, 2013.

CLARK, K.; HOLQUIST, M. Mikhail Bakhtin. São Paulo: Perspectiva, 1998.

DELEUZE, Gilles. ¿Que és un dispositivo? In: Michel Foucault, filósofo. Barcelona: Gedisa, 1990, pp. 155-161.

FAUSTO NETO, A. Como as linguagens afetam e são afetadas na circulação? In: BRAGA, J. L.; FERREIRA, J.; FAUSTO NETO, A.; GOMES, P. G. (Orgs.). 10 perguntas para a produção do conhecimento em comunicação. São Leopoldo-RS: Ed. UNISINOS, 2013, p.43-64.

A circulação das bordas. In: FAUSTO NETO, Antônio; VALDETTARO, Sandra. Mediatización, sociedade y sentido: diálogos entre Brasil y Argentina. Rosário, Argentina, Agosto 2010, p. 2-17.

2008, São Paulo, p. 89-105.

Fragmentos de uma 'analítica' da midiatização. In: Matrizes, n.2, Abril, 
FERREIRA, J. Como a circulação direciona os dispositivos, indivíduos e instituições? In: BRAGA, J. L.; FERREIRA, J.; FAUSTO NETO, A.; GOMES, P. G. (Orgs.). 10 perguntas para a produção do conhecimento em comunicação. São Leopoldo-RS: Ed. UNISINOS, 2013, p.140-155.

FERREIRA, J.; VIZER, E. (orgs.). Mídia e movimentos sociais: linguagens e coletivos em ação. São Paulo: Paulus, 2007.

GOHN, M. G. Manifestações de junho de 2013 no Brasil e praças dos indignados no mundo. Petrópolis: Vozes, 2014.

HARVEY, D. et. al. Occupy. São Paulo: Boitempo: Carta Maior, 2012.

HJAVARD, S. Midiatização: teorizando a mídia como agente de mudança social e cultural. In: Matrizes, ano 5, n 2, jan./jun. 2012: São Paulo, 2012.

JUDENSNAIDER, E. et. al. Vinte centavos: a luta contra o aumento. São Paulo: Veneta, 2013.

MARICATO, E. et al. Cidades Rebeldes: passe livre e as manifestações que tomaram as ruas do Brasil. São Paulo: Boitempo: Carta Maior, 2013.

MOLES, A. O cartaz. 2.ed. São Paulo: Perspectiva, 2004.

SAID, G. F.; DOURADO; J. L. (orgs.). O delírio é um desejo: ensaios e fragmentos sobre os protestos de junho de 2013 no Brasil. Edufpi, Teresina, 2014.

TCHAKHOTINE, S. A mistificação das massas pela propaganda política. Rio de Janeiro: Civilização Brasileira, 1997. 